\title{
Community respite service utilisation and dementia care: a review of literature
}

\section{AUTHORS}

CHERRIE JANE WAKEFIELD BSN MHS ${ }^{1}$
1 Faculty of Health Disciplines, Athabasca University, Athabasca, Alberta, Canada.

\section{CORRESPONDING AUTHOR}

CHERRIE JANE WAKEFIELD Blue Haven Care Community, 14A Bonaira Street, Kiama, NSW. 2533.

Phone: +61422420842

Email: cherriew@bluehavencare.com.au

\section{ABSTRACT}

Objective: To explore the detrimental effects of caregiver burden, in relation to caregivers of people with dementia, and highlight caregiver burden as an emerging healthcare problem. The purpose of the literature review is to inform healthcare professionals of the barriers to utilising community respite services by caregivers and discuss the significance of respite services to caregivers of people with dementia.

Background: Dementia is one of the leading contributors to burden of disease and disability. Increasing numbers of spouse and family caregivers play crucial roles in providing support for people with dementia enabling them to continue living in the community. Caregiver burden occurs in individuals when the demands of caregiving exceeds their resources. Community respite services are valuable resources which provide individuals a break from their caregiving role.

Study design and methods: The literature review will draw attention to caregivers of people living with dementia in the community and their utilisation of community respite services. The target audience are healthcare professionals in multidisciplinary community teams composed of clinicians, educators, managers, administrators, and researchers. Seven online databases were accessed to search the following terms of caregiver burden, dementia care and community respite along with specific inclusion criteria. As a result, 26 scholarly articles were reviewed for the purpose of this literature review.

Results: There are several community respite services, which help minimise the incidence of caregiver burden, available to caregivers of people with dementia but there are many barriers which affect utilisation of these services. Some of these barriers include accessibility of information on respite services, flexibility and affordability of respite services, and the caregiver's inability to recognise their need for respite services.

Discussion: Healthcare professionals could assist caregivers to better utilise community respite services by performing through assessments on both people with dementia and their caregivers. As a result of these assessments, potential barriers to community respite service utilisation could be identified.

Conclusion: Community respite services are essential to minimising the incidence of caregiver burden. Healthcare professionals should recognise these barriers to respite service use and implement strategies to increase service utilisation.

Implications for research, policy, and practice: Further research is required to investigate the specific types of respite service caregivers need and which respite services have been most successful 
for caregivers. This knowledge can assist healthcare professionals in improving utilisation rates of respite services and inform health systems on where to focus the funding of their community resources for people with dementia and their caregivers.

Key words: Caregiver burden, dementia, respite, community, literature review

What is already known about the topic?

- Dementia is an emerging healthcare problem leading to caregiver burden amongst caregivers.

- Community respite services help minimise the occurrence of caregiver burden.
What this paper adds:

- Contributes to the existing knowledge of caregiver burden amongst Australian healthcare professionals.

- Identifies several barriers to caregiver respite service utilisation.

- Emphasises the significance of respite services to caregivers of people with dementia.

\section{INTRODUCTION}

The Australian Institute of Health and Welfare ${ }^{1}$ states Australia's profile of its older population is projected to change in the coming years. In 2017, more than half of older people (57\%, or 2.2 million) were aged $65-74$, one-third were aged $75-84$ (30\%, or 1.2 million), and $13 \%$ were aged 85 and over (497,000). By 2047, it is projected there will be just under 3.4 million people aged $65-74 .{ }^{1}$ It is evident that the number of people over 65 years will continue to grow as the population ages. Dementia is the number one cause of disability in Australians aged 65 years and older and it is characterised by the gradual impairment of brain function where the skills commonly affected include memory, cognition and personality. ${ }^{2}$ Dementia presents a significant challenge to health and aged care in Australia. More than 342 ,ooo Australians are living with dementia and this number is expected to increase up to 400,000 in less than a decade. ${ }^{3}$ Worldwide, at least 44 million people are living with dementia, making the disease a global health crisis that must be addressed. ${ }^{3}$

Dementia is one of the leading contributors to burden of disease and disability, and people with dementia (PWD) are frequent users of health and aged care services. ${ }^{2}$ This progressive neurodegenerative disease is difficult for both healthcare professionals (HCPs) and family caregivers to manage. ${ }^{4}$ There are increasing numbers of spouse and family caregivers playing critical roles in providing support to PWD which enables them to remain living in their own homes. ${ }^{5-7}$ Caregivers are those who share responsibility for another person's health, wellbeing and safety over time. ${ }^{8}$ They are also unpaid individuals who support or provide informal care to a person who is dependent due to long-term physical or mental illness or to age-related problems. ${ }^{5}$ The care of PWD provided at home often involves longer hours and more intense care compared with amount of formal care provided by health services.5, ${ }^{5}$ Caregiver burden can be described as the emotional, physical, social, and financial costs that results when the demands of caregiving exceeds one's resources. ${ }^{8-12}$ This literature review highlights caregiver burden as an emerging healthcare problem as it explores the detrimental effects of caregiver burden. Furthermore, this paper aims to educate HCPs on the barriers to utilising community respite services by caregivers and discuss strategies to increase service utilisation in order to minimise caregiver burden.

\section{METHODOLOGY}

Scholarly articles were researched using the following databases CINAHL plus, Academic search complete, eBook collection, Health source - nursing/academic edition, PsycInfo, Psych articles, and Socio/index with full-text. The inclusion criteria are as follows full-text, published between 2000-2018, and peer-reviewed. Search terms used included caregiver burden, dementia care, community, respite, and Australia. The primary search strategy used the terms caregiver burden, dementia care, and community which yielded 143 articles and a total of 95 articles excluded. Research based in the United States, rural settings, and non-English speaking countries were omitted due to the unfamiliarity of the author with how community services are delivered in these areas. In addition, research based in residential care settings were omitted. The remaining 48 articles were reviewed and 30 articles were excluded as they described caregiver burden not in the context of dementia care and some articles were situated in rural communities. As a result, 18 articles were chosen for this literature review (Figure 1).

A secondary search strategy was conducted using the eight previously stated databases to capture articles based in Australia. The search terms used were caregiver burden, dementia care, community, respite, and Australia. This search yielded 26 articles and 14 articles were chosen as 12 were excluded due to lack of dementia care, non-Australian articles, and focused on a specific intervention (Figure 2). These 32 scholarly articles resulting from both searches were 


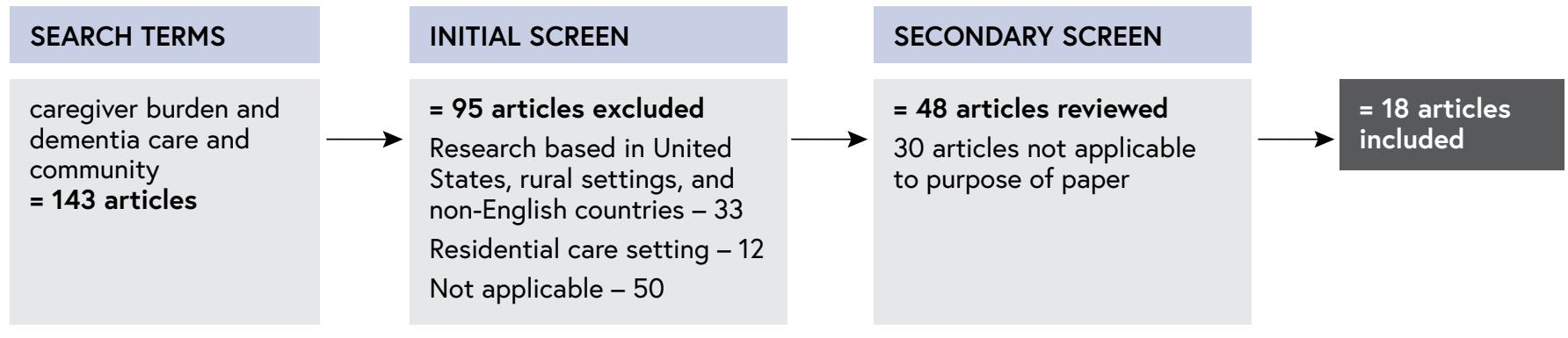

FIGURE 1: PRIMARY SEARCH STRATEGY

reviewed and sorted into two groups of caregiver burden and caregiver burden resources. Upon further review of the articles, an additional six articles were excluded as the content was found not to be suitable for this literature review. As a result, 26 scholarly articles were used for the purpose of this literature review.

\section{DISCUSSION}

\section{CAREGIVER BURDEN AND DEMENTIA CARE IN THE COMMUNITY}

Caregivers of people living with dementia experience many challenges as the disease progresses. As dementia develops, it leads to increased dependency and a consequent need for continual assistance by their caregivers. ${ }^{13,14}$ People with dementia experience disruptive symptoms such as sleep disturbances, incontinence, decreased mobility, inability to recognise family and friends, changes in sexual behaviour, disorientation, paranoia, wandering, and agitation. ${ }^{11,14,15}$ As a result of this increased dependency, caregivers can experience symptoms of burnout. Caregiver burden is a term used to describe the negative effects of caring on the person's physical, mental, social, and financial wellbeing. ${ }^{10-12,15}$ Family members, such as a spouse or adult child, usually become the caregivers of PWD, which puts added stress on their relationship especially when their loved one no longer recognises them..$^{10}$ In Australia, most people living with dementia are cared for by a family member and $25 \%$ of family caregivers provide 40 hours of care or more per week. ${ }^{16,17}$ The care they provide includes assistance with activities of daily living, such as bathing, dressing, and eating, as well as essential activities of daily living, such as money management or transportation. ${ }^{11,18}$ More than two-thirds of caregivers maintain at least 40 hours of care a week for more than 12 months, with one-third caring at that level for five years or more. ${ }^{17}$ This continuous and demanding role can have a negative effect on caregivers' mental and physical health.

\section{CAREGIVER BURDEN: AN EMERGING HEALTH ISSUE}

\section{Ageing in-place movement}

As the number of PWD rises, the number of family caregivers looking after PWD will also follow in increasing numbers. While dementia is not an inevitable part of ageing, almost $10 \%$ of Australians aged 65 or over have the condition, rising to $30 \%$ of those aged 85 and over. ${ }^{19}$ Subsequently, there will be a significant number of older people living with dementia in the coming years who will require healthcare resources both in the community and residential care. This poses significant challenges for aged care policy and services to shift from institutional care (higher-cost) to community care (lower-cost) for older people living with dementia. ${ }^{20}$ The shift in aged care policy to support community care is based on the principle of 'ageing-in-place' which enables older people to remain in their own homes longer rather than entering residential care prematurely. ${ }^{21}$ Similar to Canada, this policy shift has been supported by older people and governments however, this has redistributed care work from paid institutional carers (formal services) to unpaid carers (informal caregivers) such as family caregivers 7,20,22,23. The Australian Institute of Health and Welfare ${ }^{19}$ found the shift to 'ageing-in-place' aged care policies over the last two decades has resulted in the number of residential care places per 1,0oo persons aged 70 years and over dropping from

\section{SEARCH TERMS}

caregiver burnout and dementia care and community and respite and Australia

$=26$ articles

\section{SCREENING AND RESULTS}

$=12$ articles excluded

No dementia care -5

$=14$ articles included
Specific interventions -3

Non-Australian - 2

Rural specific - 2 
92.2 in 1995 to 86.8 in 2010 with the number of communitybased aged care places increasing from 1.7 to 24.4 over the same period. Although this change in health policy was intended to allow older people to remain in their homes longer rather than entering institutions prematurely, there has been an inadvertent negative effect on family caregivers where they may feel pressured into taking on the role of informal caregivers.7,22 The informal care provided by family caregivers assist in lowering the cost of care on health systems but it is at the cost of their own health and wellbeing if adequate support services are not in place. It is evident that community resources are needed to support family caregivers in maintaining their own health and wellbeing and to decrease the incidence of caregiver burden.

\section{The effects of caregiver burden}

Family members who care for PWD and live in the community experience high levels of stress and burden. It is well established that these caregivers often experience stress, depression, anxiety, physical illnesses, financial strain, social isolation, and poor quality of life as a result of their caregiving role. 5, , 13,14,18,23-28 The degree of functional impairment and behavioural disturbance of PWD has been shown to induce high levels of caregiver stress and lower levels of subjective wellbeing, which has been linked to higher rates of depression in caregivers. ${ }^{14,28}$ It was found that one in four caregivers of PWD contemplated suicide more than once in a previous year which was a rate more than eight times than that of the general population. ${ }^{25}$ O'Dwyer, Moyle and van Wyk found that nearly half of the participants in their study had experienced suicidal thoughts while caring and half of those made plans for a suicidal act. ${ }^{29}$ Caregivers who considered suicide 'had poorer mental health, reacted more strongly to the behavioural symptoms of dementia, and were less satisfied with the social support they were receiving'. ${ }^{25(\mathrm{p} .222)}$ Clearly, caregiver burden along with poor mental health and evidence of depression puts family caregivers of PWD at risk of suicide. It is important for HCPs to acknowledge the significance and the impact of caregiver burden for those caring for PWD.

People with dementia are commonly cared for informally by spouses or their adult children. The current demographic trend indicates that adult children are becoming primary caregivers to their ageing parents. ${ }^{27}$ In Australia, $42 \%$ of main caregivers of PWD were their spouse/partner and $44 \%$ were their son or daughter, ${ }^{19}$ while in Canada, $62 \%$ of adult children were primary caregivers to their ageing parents. ${ }^{27}$ Adult children who become caregivers to their ageing parents experience different stressors to spousal caregivers. Bastawrous explains how the provision of care by adult children is unique as there is a role reversal within this established relationship. ${ }^{27}$ The child who was once the receiver of support and nurturing must now provide the support and assistance to their parent. This role reversal not only disrupts the established relationship with the parent but combined with the other demands of caregiving can lead to hostility and resentment. ${ }^{27}$ In addition, adult child caregivers often have to negotiate the caregiver role with other family members and this can cause significant family conflict and interpersonal stress. ${ }^{24,27}$

Adult children in a caregiver role have been termed the 'sandwich generation' where they provide care for ageing parents while still supporting their own children as well as their grandchildren in some cases. ${ }^{20}$ Moreover, if these caregivers are still working, the burden of this multigenerational caregiving is compounded. They would have to prioritise their time and decide where and when the support is needed most, such as assisting their parents with their activities of daily living, while balancing their own work and family commitments. This can be difficult as adult children are typically at a stage in their lives where they have several roles and responsibilities such as being a spouse, parent and employee. ${ }^{27}$ Subsequently, work responsibilities can be viewed as contributing to caregiver stress outcomes especially if the caregiver's employment involves long hours. ${ }^{23}$ This sandwich generation of caregivers are also at the point in their lives where they have plans for advancing their career, travelling during their retirement, or pursuing their own interests..$^{20}$ The unexpected responsibility of caring for their ageing parent could affect their social and financial wellbeing.

\section{Integrated care for caregivers model}

Daniel's Integrated Care for Caregivers Model explains the factors that influence the health and wellbeing of a caregiver. ${ }^{8}$ This model describes the nine domains of education, recreation, nutrition, sleep, exercise, support, spirituality, communication, and counselling, all of which provide the supporting base for four key elements of a caregiver's health and wellbeing; physical, emotional, mental, and spiritual. ${ }^{8}$ As mentioned earlier in this paper, caregivers experience higher levels of stress and burden when these domains are negatively affected. These nine domains are fundamental in determining the health of the caregiver however education, sleep, emotional and psychological support, and counselling will be discussed further.

Daniel states family caregivers are often unprepared to provide care, have inadequate knowledge to deliver proper care, ${ }^{8}$ and are unaware of community resources available to them. It is the responsibility of HCPs to provide support and education on the skills needed for caregivers of PWD to manage their care and to discuss the community resources available to them. Caregivers' sleep patterns may be affected over time, especially with the progression of the care receiver's disease, which may exacerbate depression and symptoms of chronic illnesses. ${ }^{8}$ Healthcare professionals can ensure caregivers are taught strategies to manage the behaviours of PWD and to prevent the occurrence of 
these behaviours during the night (eg. taking them for daily walks during the day). Emotional and psychological support involves having positive interactions with a good social support network of family and friends especially under heightened stress. ${ }^{8}$ Healthcare professionals should encourage caregivers to maintain their social support and social networks in order to minimise the incidence of caregiver burden and prevent depression. It is important for caregivers to understand the need for counselling as it helps caregivers improve communication and problemsolving techniques, learn various behavioural management strategies, maintain quality care and positive outlooks. ${ }^{8}$ This model highlights the nine domains which HCPs should consider when assessing the health and wellbeing of caregivers.

\section{Significance to healthcare professionals}

It is important for HCPs to understand the caregiver experience when providing care to PWD. Caregivers often request information about dementia from prognosis to strategies on how to deal with disruptive behaviours., ${ }^{5,8}$ Healthcare professionals have a responsibility to support family caregivers by providing education and counselling to promote their wellbeing. Educating caregivers is important as it empowers caregivers through knowledge and it is a way of supporting caregivers in their demanding role.5,30 Moreover, HCPs are fundamental in providing ongoing emotional support to caregivers especially when they are faced with making difficult care decisions. ${ }^{31}$ As mentioned earlier in this paper, it is essential for HCPs to recognise poor mental health in the presence of caregiver burden as it can lead to suicidal thoughts in caregivers. This can be a strong indicator of the caregiver's physical and emotional suffering warranting prompt intervention from HCPs.

Supporting caregivers in their challenging role has many benefits for caregivers, PWD, and healthcare systems. The significance of HCP involvement in decreasing the incidence of caregiver burden is that 'placement in residential care facilities has been associated with rapid deterioration in health, psychosocial challenges for patients and families, and increased mortality'. ${ }^{10(p .24)}$ Consequently, the ability for those living with dementia to remain in their homes longer with community support services delays institutionalisation and decreases mortality. ${ }^{4,10}$

\section{COMMUNITY RESPITE SERVICES}

People with dementia eventually decline physically and mentally affecting their ability to perform their activities of daily living. Vreugdenhil found that caregivers of PWD assisted with a wide range of activities which included selfcare, meal preparation, transport, and communication. ${ }^{20}$ Informal caregivers require formal services because caring for PWD can be complex, demanding, and at times assistance is needed around the clock. Formal services, which support caregivers in managing the people they care for, are referred to as respite services or respite care. Respite is defined as a pause, a temporary cessation, or an interval of rest. ${ }^{22}$ Tretteteig found in their review that caregiver burden is significant and gives rise to a great need for support and help. ${ }^{13}$ Respite care is a way of supporting caregivers and delaying institutionalisation. 6,13,14,30,31 It is also essential in the home management of PWD as it helps to decrease stress related to the demands of caring and also allows time for caregivers to rest and do things for themselves. ${ }^{31}$ This temporary relief of their burden of care enables them to attend to basic everyday needs such as attending to their own healthcare, shopping, and social needs. ${ }^{6}$ O'Connell and colleagues found that four out of five caregivers in their study stated that they had experienced lower stress levels since utilising respite services and more than half reported that their own health had improved since using the service. ${ }^{6}$ Utilising respite services is crucial to the health and wellbeing of the caregiver and it could possibly lengthen their ability to care for PWD in their own home.

There are several types of respite services in the community which can be utilised in crisis situations or in part of a planned regular service to provide custodial care. The most common types of respite used are at a day centre, within the home, and at residential care. ${ }^{6,14,3^{\circ}}$ In-home respite involves community health workers assisting PWD with their activities of daily living or simply watching over them in their home while their caregiver leaves for a much-needed break. Day centre respite involves PWD attending for a set period time to participate in planned activities whereas residential care respite involves a short stay, such as a week, within the facility. ${ }^{6,14}$

\section{BARRIERS TO UTILISING RESPITE SERVICES}

Clearly, there is a significant amount of research and systematic reviews on caregiver burden, dementia care and respite services in the community however there was limited research on why caregivers underutilise community respite services despite its benefits in reducing caregiver burden. Caregivers face many challenges when caring for PWD and HCPs may assume caregivers would regularly utilise the community resources available to them. Throughout the reviewed literature, it was evident that respite services were underutilised due to several key barriers. Caregivers were reluctant to utilise essential support services because of their negative emotions of grief, sadness, or frustration or they were unable to identify that their stress was directly linked to the care recipient. ${ }^{11,12,18,32}$ Furthermore, caregivers lacked the knowledge of respite services available to them. ${ }^{5,8,12,14,32,33}$ Eifert and Eddy also found some caregivers chose not to utilise respite services because they wanted to keep their loved one's diagnosis private and any acceptance of help from outside the family was seen as an invasion of privacy. ${ }^{11}$ 
In contrast, when caregivers utilised respite services, they discovered barriers themselves that prevented or limited further respite service use. Caregivers found respite services were inflexible or unreliable in their delivery times and it did not meet their needs. 6,12,14,18,22,32,33 Caregivers reported that there was a greater amount of work generated when preparing PWD for respite and this caused the caregiver more stress. ${ }^{11,32}$ Caregivers also stated that managing the behaviour of PWD post-respite service use resulted in disruptive behaviours, such as resisting care or aggression, causing additional caregiver stress. ${ }^{6,11,14}$ This interruption of the PWD's routine outweighed the benefits of utilising respite services as perceived by their caregivers. Lastly, caregivers expressed concerns of the cost of respite services and utilisation these services depended on caregiver affordability. ${ }^{6,11,33}$

\section{STRATEGIES TO INCREASE RESPITE SERVICE UTILISATION}

Current health policy dictates that one of its key goals is to delay the institutionalisation of PWD however there is overwhelming evidence that community resources should consider not only the care of PWD but also the health and wellbeing of their caregivers. The benefits of broadening the focus of care will help sustain caregivers to continue caring for PWD in their own home for years to come. HCPs have a significant role in performing thorough assessments on both PWD and their caregiver. These assessments will help identify any knowledge gaps in relation to physically and mentally caring for PWD and communicate vital information on the community respite services available to caregivers. The contact with caregivers and PWD during these assessments gives HCPs the opportunity to offer ongoing emotional support to both the caregiver and PWD. As the relationship between HCPs and caregivers develops over time, HCPs are in a position to identify when additional support is needed, such as counselling through a social worker or the initiation of respite services. This established and long-standing relationship between HCPs and caregivers facilitates continuous communication where caregivers are able to inform HCPs of any issues they might encounter in relation to respite services, such as inflexibility, unreliability, and unaffordability. ${ }^{32}$ Healthcare professionals should work with the community multidisciplinary team to address the barriers of specific services with the goal of increasing respite service utilisation by caregivers. Furthermore, HCPs should help caregivers create a plan of care following respite service use to address disruptions and behaviours of PWD and minimise caregiver stress post-respite.

\section{RECOMMENDATIONS FOR FUTURE RESEARCH}

There is limited knowledge on which respite services have been beneficial to caregivers as the articles that were reviewed only described the respite services in relation to PWD and not their caregivers. Additional research is required to investigate the specific types of respite service caregivers need and which respite services have been most successful for caregivers. This knowledge can assist HCPs in improving utilisation rates of respite services and inform health systems on where to focus the funding of their community resources for PWD and their caregivers.

\section{CONCLUSION}

Caregiver burden is undoubtedly a prominent health issue which will persist as the population continues to age and the number of PWD increases. Caregivers of PWD partake in a demanding role which impacts their own health and wellbeing. Subsequently, health systems are responsible in providing support to these informal caregivers since they delay the use of formal services, such as residential care, and help PWD remain in their own homes longer. HCPs should perform thorough assessments of both the caregiver and PWD to maintain their health and wellbeing and to encourage the use of respite services. Furthermore, HCPs must identify the barriers to respite service utilisation by caregivers so that strategies are implemented and the incidence of caregiver burden is reduced.

Funding support: This manuscript was prepared in relation to the completion of a Masters in Health Studies program. The author did not receive funding to complete this work.

Declaration of conflicting interests: There are no conflicts of interest in relation to this manuscript.

\section{REFERENCES}

1. Australian Institute of Health and Welfare. Older Australia at a glance. 2018. Available online: https://www.aihw.gov.au/ reports/older-people/older-australia-at-a-glance/contents/ demographics-of-older-australians/australia-s-changing-agegender-profile (accessed 18 Oct 2018)

2. Australian Institute of Health and Welfare. Australia's Health 2016. 2016. Available online: https://www.aihw.gov.au/reports/ australias-health/australias-health-2016/contents/chapter-3leading-causes-of-ill-health (accessed 18 Oct 2018)

3. Alzheimer's Association. Alzheimer's and Dementia in Australia. 2018. https://www.alz.org/au/dementia-alzheimers-australia. asp (accessed 18 Oct 2018)

4. Hum S, Cohen C, Persaud M, et al. Role Expectations in Dementia Care Among Family Physicians and Specialists. Can Geriatr J. 2014; 17(3): 95-102. https://doi.org/10.5770/cgj.17.110

5. Lethin C, Hallberg IR, Karlsson S, Janlov A. Family Caregivers' Experiences of Formal Care when Caring for Persons with Dementia Through the Process of the Disease. Scand J Caring Sci. 2016; 30: 526-534. https://doi.org/10.1111/scs.12275 
6. O'Connell B, Hawkins M, Ostaszkiewicz J, Millar L. Carer's Perspectives of Respite Care in Australia: An evaluative study. Contemp Nurse. 2012; 41(1): 111-119. https://doi.org/10.5172/ conu.2012.41.1.111

7. Moyle W, Edwards H, Clinton M. Living with Loss: Dementia and the family caregiver. Aust J of Adv Nurs. 2002; 19(3): 25-31. http://www.ajan.com.au/ajan 19.3.html

8. Daniel N. Integrating Care for Caregivers. Nurs N Z. 2014; 20(10): 28-29. http://0-web .b.ebscohost. com.aupac.lib.athabascau.ca/ehost/pdfviewer/ pdfviewer?vid=11\&sid=ac7f21ec-8501-4cd7-bd06$421 \mathrm{e} 30 \mathrm{dbd} 218 \% 40$ sessionmgr101

9. Aoun SM, Toye C, Slatyer S, Robinson A, Beattie E. A Personcentred Approach to Family Carer Needs Assessment and Support in Dementia Community Care in Western Australia Health Soc Care Community. 2018; 26: 578-586. https://doi. org/10.1111/hsc. 12575

10. Hanna A, Donnelly J, Aggar C. Study Protocol: A montessori approach to dementia-related, non-residential respite services in Australia. Arch Gerontol Geriatri. 2018; 77(2018): 24-30. https://doi.org/10.1016/j.archger. 2018.03.013

11. Eifert EK, Eddy J. The Role of Needs Assessments in Enhancing Support Service Utilization by Family Caregivers of Persons with Alzheimer's Disease. Am J Health Stud. 2012; 27(4): 227-235. http://0-web.b.ebscohost.com.aupac.lib.athabascau.ca/ehost/ pdfviewer $/$ pdfviewer?vid=4\&sid=2cf9d01d-3ff6-4d3f-a07c1af1b09beca3\%40pdc-v-sessmgr01

12. Stirling C, Andrews $S$, Croft T, Vickers J, Turner P, Robinson A Measuring Dementia Carers' Unmet Need for Services - An exploratory mixed method study. BioMed Central. 2010; 10(122): 1-10. https://doi.org/10.1186/1472-6963-10-1222

13. Tretteteig S, Vatne S, Rokstad AM. The Influence of Day Centres for People with Dementia on Family Caregivers: An integrative review of the literature. Aging Ment Health. 2016; 20(5): 450462. https://doi.org/10.1080/13607863.2015.1023765

14. Tang J, Ryburn B, Doyle C, Wells Y. The Psychology of Respite Care for People with Dementia in Australia. Clin Psychol. 2011; 46(2011): 183-189. https://doi.org/10.1111/j.17429544.2010.00005.x

15. Australian Institute of Health and Welfare. Dementia in Australia: National data analysis and development. Canberra, ACT; 2007. Available online: https://www.aihw.gov.au/ getmedia/bb7f4ad4-9879-4ce7-8b6b-fa3ca1ca3866/dandad. pdf.aspx?inline=true (accessed 18 Oct 2018)

16. Access Economics. Caring places: Planning for aged care and dementia 2010-2050. Canberra: Alzheimer's Australia; 2010. Available online: http://www.fightdementia.org.au/researchpublications/access-economics-reports.aspx (accessed 18 Oct 2018).

17. Access Economics. Making choices: Future dementia care projects, problems and preferences. Canberra: Alzheimer's Australia; 2009. Available online: http://www.fightdementia. org.au/research-publications/access-economics- reports.aspx (accessed 18 Oct 2018).

18. McCabe M, You E, Tatangelo G. Hearing their Voice: A systematic review of dementia family caregivers' needs. Gerontologist. 2016; 56(5): 70-88. https://doi.org/10.1093/ geront/gnw078

19. Australian Institute of Health and Welfare. Residential Aged Care in Australia 2009-10: A statistical overview. 2011. Available online: http://www.aihw.gov.au/publicationdetail/?id=10737419861 (accessed 18 Oct 2018).
20. Vreugdenhil A. 'Ageing-in-place': Frontline experiences of intergenerational family carers of people with dementia. Health Sociol Rev. 2014; 23(1): 43-52. https://doi.org/10.5172/ hesr.2014.23.1.43

21. Australian Government Department of Health and Ageing. Living Longer, Living Better: Aged care reform package. 2012. Available online: http://www.health.gov.au/internet/ publications/publishing.nsf/Content/ageing-aged-care-reformmeasures-toc (accessed 18 Oct 2018).

22. Lilly MB, Robinson CA, Holtzman S, Bottoroff JL. Can We Move Beyond and Burnout to Support the Health and Wellness of Family Caregivers to Person with Dementia? Evidence from British Columbia, Canada. Health Soc Care Community. 2012; 20(1): 103-112. https://doi.org/10.1111/j.1365-2524.2011.01025.x

23. Bainbridge HT, Cregan C, Kulik CT. The Effect of Multiple Roles on Caregiver Stress Outcomes. Int J of Appl Psychol. 2006. 9(2): 490-497. https://doi.org/10.1037/0021-9010.91.2.490

24. Tatangelo G, McCabe M, Macleod A, Konis A. I Just Can't Please Them All and Stay Sane: Adult child caregivers' experiences of family dynamics in care-giving for a parent with dementia in Australia. Health Soc Care Community. 2017; 26: 370-377. https://doi.org/10.1111/hsc.12534

25. O'Dwyer ST, Moyle W, Zimmer-Gembeck M, De Leo D. Suicidal Ideation in Family Carers of People with Dementia. Aging Ment Health. 2016; 20(2): 222-230. https://doi.org/10.1080/1360786 3.2015.1063109

26. Peetoom KB, Lexis MA, Joore M, Dirksen CD, Witte LP. The Perceived Burden of Informal Caregivers of Independently Living Elderly and their Ideas About Possible Solutions. A mixedmethods approach. Technol and Disabil. 2016; 28(2016):19-29. https://doi.org/10.3233/TAD-160441

27. Bastawrous M, Gignac MA, Kapral MK, Cameron JI. Factors that Contribute to Adult Children Caregivers' Well-being: A scoping review. Health Soc Care Community. 2015; 23(5): 449-466. https://doi.org/10.1111/hsc.12144

28. Martin Y, Gilbert P, Mcewan K, Irons C. The Relation of Entrapment, Shame and Guilt to Depression, in Carers of People with Dementia. Aging Ment Health. 2006; 10(2): 101-106. https://doi.org/10.1080/13607860500311953

29. O'Dwyer S, Moyle W, van Wyk S. Suicidal Ideation and Resilience in Family Carers of People with Dementia: A pilot qualitative study. Aging Ment Health. 2013; 17(6): 753-760. https://doi.org/10.1080/13607863.2013.789001

30. Singh P, Hussain R, Khan A, Irwin L, Foskey R. Dementia Care: Intersecting informal family care and formal care systems. Journal Aging Res. 2014; 2014: 1-9. https://doi. org/10.1155/2014/486521

31. Shanley C, Fetherstonhaugh D, McAuliffe L, Bauer M, Beattie E. Providing support to Surrogate Decision-makers for People Living with Dementia: Healthcare professional, organizational and community responsibilities. Health Soc Care Community. 2017; 25: 1563-1570. https://doi.org/10.1111/hsc.12456

32. Neville C, Beattie E, Fielding E, MacAndrew M. Literature Review: Use of respite by carers of people with dementia. Health Soc Care Community. 2015. 23(1): 51-63. https://doi. org/10.1111/hsc.12095

33. Ward-Griffin C, Hall J, DeForge R, et al. Dementia Home Care Resources: How are we managing? J Aging Res. 2012; 2012: 1-11. https://doi.org/10.1155/2012/590724 